\title{
A Community Study on Attitudes to and Knowledge of Mental Illness in Tehran
}

\author{
Helia Ghanean ${ }^{1 *}$, Marzieh Nojomi², Lars Jacobsson ${ }^{1}$ \\ ${ }^{1}$ Department of Psychiatry, Umeå University, Umeå, Sweden \\ ${ }^{2}$ Tehran Medical University, Tehran, Iran \\ Email: " helia.ghanean@psychiat.umu.se
}

Received 24 September 2014; revised 20 October 2014; accepted 18 November 2014

Academic Editor: Gjumrakch Aliev, University of Atlanta, USA

Copyright (C) 2015 by authors and Scientific Research Publishing Inc.

This work is licensed under the Creative Commons Attribution International License (CC BY). http://creativecommons.org/licenses/by/4.0/

(c) () D Den Access

\section{Abstract}

There are a limited number of studies on attitudes towards mental illness and mentally ill from Islamic countries even though Islam is the second largest of the religious beliefs in the world. An interesting element in Islamic teaching is the idea that mental illness as well as other ailments might be an effect of the will of Allah. This could imply that persons suffering from mental disorders might be less stigmatized. The aim of this study was to determine the knowledge and attitudes towards mental illness in the city of Tehran, Iran. Eight hundred subjects, randomly chosen from 4 districts of Tehran, responded to a modified version of a questionnaire developed by the World Psychiatric Association to reduce stigma because of schizophrenia. The self-completed questionnaire was delivered by 4 trained psychologists. The mean age of the sample was 37.5 years and $53.3 \%$ being males. A majority agreed that mental illness could be treated outside the hospital (70\%) and $74 \%$ thought that mentally ill "can work in regular jobs". Almost half agreed that "mentally ill are a public nuisance" and that "mentally ill people are dangerous". One quarter agreed that they "would be ashamed if people knew someone in the family who was diagnosed with mental illness". Generally males seemed to be more accepting than women. Generally the level of negative attitudes in Tehran population is at the same level as in other countries and cultures studied. Cultural beliefs and Islamic influence on attitudes towards mental illness and mentally ill need further studies. The result indicates a need for further actions to reduce the negative attitudes towards mentally ill in Tehran, Iran.

\section{Keywords}

Mental Illness, Public Attitudes, Iran

\footnotetext{
${ }^{*}$ Corresponding author.
} 


\section{Introduction}

Mental illnesses are among the most stigmatizing conditions worldwide. The reasons for this are obvious. A common stereotype is that people with serious mental illness might behave peculiar and sometimes even frightening. The majority of persons suffering from mental disorders, however, do not behave in a conspicuous way. Instead, people with depression, anxiety disorders, and most persons suffering from psychotic disorders, are silent and withdrawn. This and other stereotypes depend, in part, on the cultural context; what is perceived as a mental disorder, what is known, and what is believed about the background and the nature of different expressions of mental distress. People who have a mental disorder tend to be discriminated against in several ways. They often withdraw from their family and society and they avoid asking for help. This increases the burden of illness both for the person with the disorder, but also for their families and friends. The costs for the society are enormous and at least partly a result of the stigma attached to mental disorders [1].

There is a considerable amount of research on the nature of stigma because of mental illness and its consequences. Most of these studies have been performed in western industrialized countries with more or less developed services for mentally ill [2]. However, mental disorders are also prevalent in low and middle income countries, many with traditional cultures, and the level of stigma is also high in these milieu [3] [4]. Much less is known about the attitudes towards people with a mental illness in other cultures. For example, there are a limited number of studies from Islamic countries even though Islam is the second largest of the religious belief systems in the world. An interesting element in Islamic teaching is the idea that mental illness as well as other ailments might be an effect of the will of God and not necessarily a punishment for sins [5]. This could imply that persons suffering from mental disorders might be less stigmatized because their way of life and behavior might not be viewed as the result of personal defaults. In order to contribute to this small body of international literature, the aim of this study was to investigate public knowledge, attitudes, and practices towards mentally ill persons in Tehran, Iran.

\section{Methods}

The study was conducted in Tehran, the capital of Iran. Iran is an Islamic republic with strict adherence to Islamic teaching and tradition. The majority belongs to the Shia direction of Islam. The educational level of the population in Tehran is rather high. There are quite a number of children and youngsters in the population making the mean age low. The health care system in Tehran and Iran is well developed and there are a number of specialized services for psychiatric patients. Psychiatry is also included in the primary health care system [6].

According to the Tehran Municipality, Greater Tehran has almost 12 million inhabitants. The city of Tehran is divided into 22 districts and 112 sub-districts (Nahiyeh). There are also smaller sub-divisions such as "howzeh"/blocks. A multi-stage sampling method was used. We randomly selected 4 northern districts, 4 eastern districts, 4 western districts, and 4 southern districts. Within each district, we randomly chose 4 blocks, and from each block, 50 inhabitants were selected starting from the southwest street of that block. One person over 15 years old with reading and writing knowledge was randomly selected from each household (cointoss). A sample of 600 to 800 individuals was considered necessary for the study. A total of 800 individuals were collected.

A modified version of a questionnaire developed for the World Psychiatric Association program to reduce stigma and discrimination because of Schizophrenia was used [7]. This modified version was developed by a research group in Nigeria headed by Professor Gureje [8]. We have used the questionnaire with permission from Professor Gureje in order to be able to compare our results. The original questionnaire was focused on knowledge of and attitudes to schizophrenia. This was modified by substituting "schizophrenia" with the term "mental illness". This modified questionnaire contains 6 socio-demographic questions, 11 questions regarding knowledge and attitudes, and 1 open ended question about cause of mental illness. More specific items related to schizophrenia were deleted. The questionnaire was translated into Persian, and back translated to English by Psychiatrists with good knowledge of English.

The questionnaire was delivered by four trained psychologists ( 2 women and 2 men) from the university. The psychologists were present during data collection and assisted subjects to complete the questions, if needed. Data collection took place during mornings and afternoons on week days and holidays between April and December 2009 (Persian calendar 1388).

The project was approved by the ethics committee of the Medical School of the Tehran University of Medical Sciences. The study was conducted in accordance with the Helsinki declaration on research ethics. Participation was voluntary and the responses anonymous. As well as obtaining permission from the ethics committee we ob- 
tained approval of the police, with their written consent to show participants.

\section{Results}

The study population is presented in Table 1 . The mean age of the sample was 37.5 years (range 15 - 85 years) and $53.3 \%$ were males. With respect to educational level, the majority had 12 years or more of schooling.

In Table 2 is shown perceived causes of mental illness. Nearly $80 \%$ indicated two or more alternatives as alcohol, drugs, stress and heredity. Twenty-one percent indicated only one possible cause. For example proposed $1.3 \%$ the will of God as the single cause.

A number of questions covered views about people with mental illness. In Table 3 are given the proportion

\section{Table 1. Socio-demographic background of the population.}

\begin{tabular}{|c|c|c|}
\hline & Males (\%) $\mathrm{N}=426$ & Females $(\%) \mathrm{N}=374$ \\
\hline \multicolumn{3}{|l|}{ Age } \\
\hline$<25$ years & 24.4 & 24.5 \\
\hline $26-45$ years & 38.7 & 38.2 \\
\hline $46-60$ years & 29.2 & 34.0 \\
\hline$>60$ years & 7.7 & 3.3 \\
\hline Missing & (0) & \\
\hline \multicolumn{3}{|l|}{ Education } \\
\hline$<$ Diploma (<12 years) & 23.0 & 23.8 \\
\hline Diploma (12 years) & 38.5 & 35.6 \\
\hline >Diploma (>12 years) & 38.5 & 40.6 \\
\hline Missing & $(0)$ & \\
\hline \multicolumn{3}{|l|}{ Marriage } \\
\hline Single & 40.4 & 30.7 \\
\hline Ever married & 59.6 & 69.3 \\
\hline Missing & $(0)$ & \\
\hline \multicolumn{3}{|l|}{ Occupation } \\
\hline Employed & 74.4 & 31.8 \\
\hline Not in the labour market (unemployed; housewife, etc.) & 25.6 & 68.2 \\
\hline Missing & (0) & \\
\hline
\end{tabular}

Table 2. Causes of mental illness in public view $(\mathrm{N}=800)$.

\begin{tabular}{cc}
\hline & $\%$ \\
\hline Alcohol or drug & 22.6 \\
Traumatic physical event or shock & 45.2 \\
Psychological trauma & 39.6 \\
Stress & 69.8 \\
Genetics & 26.4 \\
Physical abuse & 15.1 \\
Evil spirits & 5.6 \\
Environmental factors & 26.4 \\
Will of God & 5.6 \\
Brain disease & 33.9 \\
\hline
\end{tabular}

\section{Table 3. Views about people with mental illness.}

\begin{tabular}{ccc}
\hline Public views on mental illness & Tehran $(\%)(\mathrm{N}=800)$ Nigeria $(\%)(\mathrm{N}=2040)$ \\
\hline Do you think mental illness can be treated outside hospital? & 70 & 21 \\
Do you think that people with mental illness tend to be mentally retarded? & 45.0 \\
Do you think people with mental illness are a public nuisance? & 74.5 \\
Do you think that people with mental illness can work in regular jobs? & 52.2 \\
Do you think that people with mental illness are dangerous because of violent behavior? & 25.5 \\
\hline
\end{tabular}


endorsing the items and the figures from the Nigerian study [8] as a comparison.

A majority of the Tehran subjects agreed that mental illness can be treated outside the hospital. A minority thought that people with a mental illness "tend to be mentally retarded". Almost half, however, agreed that people with a mental illness "are a public nuisance". A majority (74\%) thought that people with a mental illness "can work in regular jobs". Half agreed that people with a mental illness "are dangerous". There are no significant differences in responses as regards gender, age, education or marital status.

Table 4 shows the proportion endorsing a number of questions on attitudes towards mentally ill persons. The responses in the Nigerian study are given as comparison.

There is an obvious ambivalence in the responses. On one hand there is a rather positive view as concerns being friend, having a conversation or not being ashamed of having a mentally ill in the family. On the other hand $40 \%$ report being upset working on the same job and $31 \%$ are unwilling to share room. The Nigerian sample however showed much more negative attitudes in all aspects covered.

\section{Discussion}

The concept of mental illness used in this study is ambiguous. "Mental illness" (Ravani) can mean a lot of things, from mild depression to severe schizophrenia. We have used this concept in order to be able to compare our results with results from studies in other countries and cultures that have used this approach. As "a substantial part of the public can not recognize specific mental disorders" [2], it is reasonable to use this broad concept of "mental illness". As the questions in our questionnaire have been used in many studies over the years we have not made any attempt to assess the validity or reliability of the questions.

In general the responses to the different questions on attitudes and knowledge are similar to those found in other studies from industrialized countries as well as low income countries, even though much less negative than in the Nigerian sample. This may be a result of the higher educational level in the Iranian group. The idea that mentally ill persons are dangerous seems to be a widely shared perception. In a Swedish study from 2003, for example, 51\% agreed that "most people with mental disorders commit violent acts more than others". This number was even higher than in a study performed in 1976 [9]. Almost half of the population also agreed to the statement that people with a mental illness are a "public nuisance". On the other hand people were more positive to the idea that mentally ill can be treated outside hospital (70\%) and that people with a mental illness "can work in regular jobs” (74\%). In a study on public attitudes among Qatari and other Arab expatriates, 53.5\% agreed that mentally ill are dangerous whereas only $33.6 \%$ thought that mentally ill could work in regular jobs [10].

Angermeyer and Dietrich conclude in their review on public attitudes that "we are still far from evidencebased anti-stigma programs" [2]. However Mansouri et al. in a review on the effect of education on attitudes and knowledge of mental health in different settings in Iran conclude that there is evidence of improved knowledge and attitudes of the population after intervention programs [11].

The idea that social stigma might be less prevalent in Islamic societies than in modern western societies is not necessarily supported by this study.

\section{Conclusion}

In conclusion, the level of negative attitudes in this Tehran population is at the same level as in other countries

Table 4. Attitudes towards persons with a mental illness.

\begin{tabular}{ccc}
\hline Public attitude towards mental illness & Tehran (\%) (N=800) & Nigeria (\%) (N= 2040) \\
\hline Would you be afraid to have a conversation with him/her? & 17 & 82.7 \\
Would you be upset or disturbed about working on the same job? & 40 & 78.1 \\
Do you think it is possible to maintain a friendship with such a person? & 68 & 16.9 \\
Would you be unwilling to share a room with her/him? & 31 & 81.2 \\
Would you be ashamed if people knew someone in your family been diagnosed with & 24 & 12 \\
Would you marry someone with a mental illness? & 3.4 \\
\hline
\end{tabular}


and cultures studied. However compared to Nigeria there seems to be a lower level of stigmatization towards mentally ill persons, which is reasonably a consequence of a higher educational level in Iran. There are reasons to think about anti-stigma activities also in Tehran and possibly Iran in general. However, this approach must not just be a single project-it is necessary to have a continuous character. The question whether Islam has a more positive impact on attitudes towards mental illness and mentally ill, needs further studies.

\section{Acknowledgements}

The support from Professor Joghataei is highly appreciated.

\section{Funding}

This study was financially supported by Tehran University of Medical Sciences and Health Services.

\section{References}

[1] Sartorius, N. (2007) Stigma and Mental Health. Lancet, 370, 810-811. http://dx.doi.org/10.1016/S0140-6736(07)61245-8

[2] Angermeyer, M.C. and Dietrich, S. (2006) Public Beliefs about and Attitudes towards People with Mental Illness: A Review of Population Studies. Acta Psychiatrica Scandinavica, 113, 163-179. http://dx.doi.org/10.1111/j.1600-0447.2005.00699.x

[3] Fabrega Jr., H. (1991) Psychiatric Stigma in Non-Western Societies. Comprehensive Psychiatry, 32, 534-535. http://dx.doi.org/10.1016/0010-440X(91)90033-9

[4] Naeem, F.M. (2006) Stigma and Psychiatric Illness. A Survey of Attitudes of Medical Students and Doctors in Lahore, Pakistan. Journal of Ayub Medical College Abbottabad, 18, 46-49.

[5] Bolhari, J., Nouri Ghassem Abadi, R. and Ramezani Farani, A. (2002) In: Hussain Khan, Z., Ed., Quranic Verses on Mental Health for Mental Health Workers and School Counselors, Office for Islamic Studies of Mental Health, Tehran, 22.

[6] Yasamy, M.T., Shahmohammadi, D., Bagheri-Yazdi, S.A., Layeghi, H., Bolhari, J., Razzaghi, E.M., Bina, M. and Mohit, A. (2001) Mental Health in the Islamic Republic of Iran: Achievements and Areas of Need. Eastern Mediterranean Health Journal, 7, 381-391.

[7] Stuart, H., Koller, M. and Milev, R. (2008) Inventories to Measure the Scope and Impact of Stigma Experiences from the Perspective of Those Who Are Stigmatized-Consumer and Family. In: Arboleda-Florez, J. and Sartorius, N., Eds., Understanding the Stigma of Mental Illness, John Wiley \& Sons Ltd., London, 193-204. http://dx.doi.org/10.1002/9780470997642.app1

[8] Gureje, O., Lasebikan, V.O., Ephraim-Oluwanuga, O., Olley, B.O. and Kola, L. (2005) Community Study of Knowledge of and Attitude to Mental Illness in Nigeria. British Journal of Psychiatry, 186, 436-441. http://dx.doi.org/10.1192/bjp.186.5.436

[9] Ineland, L., Jacobsson, L., Salander Renberg, E. and Sjölander, P. (2008) Attitudes towards Mental Disorders and Psychiatric Treatment-Changes over Time in a Swedish Population. Nordic Journal of Psychiatry, 62, 192-197. http://dx.doi.org/10.1080/08039480801962855

[10] Ghuloum, S., Bener, A. and Burgut, F.T. (2010) Epidemiological Survey of Knowledge, Attitude and Health Literacy Concerning Mental Illness in a National Community Sample: A Global Burden Disease. Journal of Primary Care and Community Health, 1, 111-118.

[11] Mansouri, N., Gharaee, B., Shariat, S.V., Bolhari, J., Yousefi Nooraie, R., Rahimi-Movaghar, A. and Alirezaie, N. (2009) The Change in Attitude and Knowledge of Health Care Personnel and General Population Following Trainings Provided during Integration of Mental Health in Primary Health Care in Iran: A Systematic Review. International Journal of Mental Health Systems, 3, 15. http://dx.doi.org/10.1186/1752-4458-3-15 
Scientific Research Publishing (SCIRP) is one of the largest Open Access journal publishers. It is currently publishing more than 200 open access, online, peer-reviewed journals covering a wide range of academic disciplines. SCIRP serves the worldwide academic communities and contributes to the progress and application of science with its publication.

Other selected journals from SCIRP are listed as below. Submit your manuscript to us via either submit@scirp.org or Online Submission Portal.
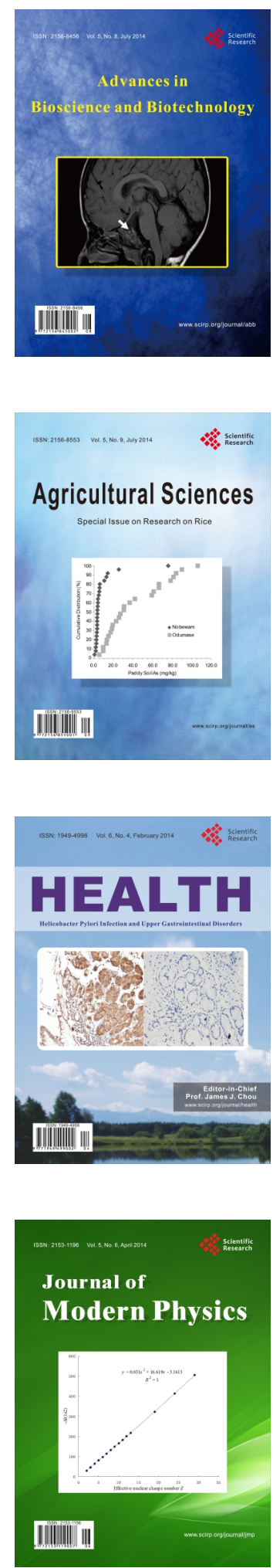
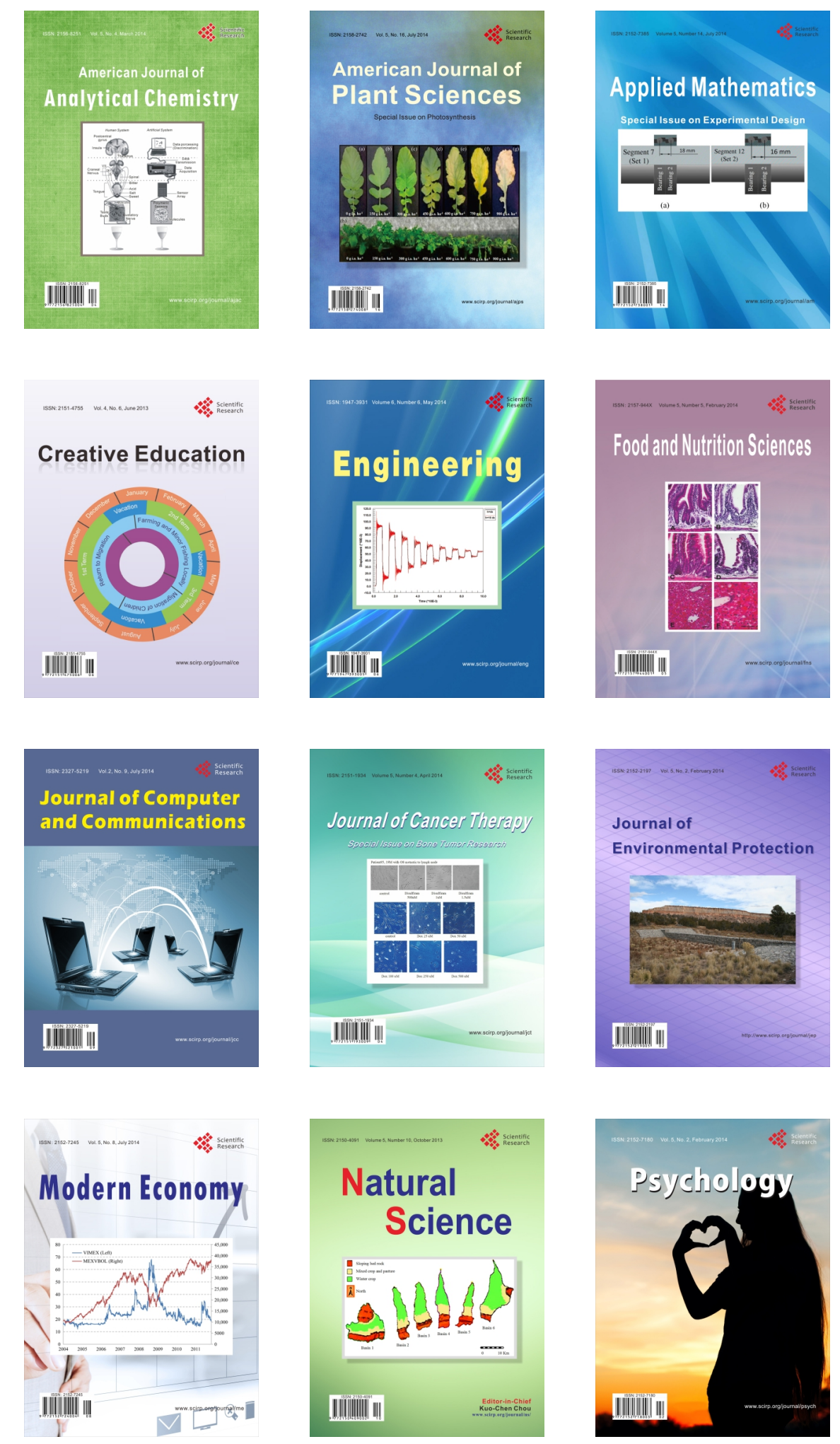